Check for updates

Cite this: RSC Adv., 2018, 8, 13417

Received 23rd February 2018 Accepted 3rd April 2018

DOI: $10.1039 / \mathrm{c} 8 \mathrm{ra01620h}$

rsc.li/rsc-advances

\section{Hypercrosslinked porous polymers hybridized with graphene oxide for water treatment: dye adsorption and degradation $\dagger$}

\author{
Yipeng Huang, $\dot{t}^{\mathrm{a}}$ Guihua Ruan, (D) *ab Yuji Ruan, $\stackrel{t}{+}^{\mathrm{c}}$ Wenjuan Zhang, ${ }^{\mathrm{a}}$ Xianxian Li, ${ }^{\mathrm{a}}$ \\ Fuyou Du, ${ }^{\text {ab }}$ Cunjie $\mathrm{Hu}^{\mathrm{a}}$ and Jianping $\mathrm{Li}$ iD ab
}

\begin{abstract}
Hypercrosslinked porous polymer hybridized graphene oxide with polymeric high internal phase emulsions (polyHIPEs/GO) were designed as versatile composites for water treatment. Morphologies, chemical composition and thermal stability of the composites were characterized by SEM, FTIR, XPS, XRD and TGA. Tunable adsorption properties and enhanced visible-light photocatalysis towards organic dyes were achieved by the manipulation of functional groups and the inclusion of $\mathrm{Ag}_{3} \mathrm{PO}_{4}$, respectively. The adsorption capacity of polyHIPEs/GO towards cationic methyl blue (MB) and rhodamine B (RB) is 1250.3 and $1054.1 \mathrm{mg} \mathrm{g}^{-1}$, respectively. Aminated polyHIPEs/GO (polyHIPEs $\left(\mathrm{NH}_{2}\right) / \mathrm{GO}$ ) possesses an adsorption capacity of $1967.3 \mu \mathrm{g} \mathrm{g}^{-1}$ to anionic eosin $\mathrm{Y}(\mathrm{EY})$. The tandem columns of polyHIPEs$\left(\mathrm{NH}_{2}\right) / \mathrm{GO}$ and polyHIPEs/GO can successively and selectively remove the cationic and anionic dyes in a mixed dye solution. Furthermore, enhanced photodegradation ability was obtained after $\mathrm{GO}$ reduction and $\mathrm{Ag}_{3} \mathrm{PO}_{4}$ addition on polyHIPES$\left(\mathrm{NH}_{2}\right) / \mathrm{GO}$. Results show that $3.5 \times 10^{-5} \mathrm{M}$ of $\mathrm{MB}, \mathrm{RB}$ and $\mathrm{EY}$ can be completely photodegraded by $20 \mathrm{mg}$ of the novel photocatalyst within 20, 40 and $35 \mathrm{~min}$, respectively. This work demonstrates that polyHIPEs/GO exhibits tunable properties for multiply progressive applications in water treatment and catalysis.
\end{abstract}

\section{Introduction}

Graphene has attracted significant attention in many disciplines due to its impressive surface area, extreme mechanical strength, high thermal and high electron mobility. ${ }^{1,2}$ Assembling 2D graphene derivatives into macroscopic 3D structures is an essential step to expand their practical applications in oil or contaminant treatment, ${ }^{3-5}$ catalysis, ${ }^{6,7}$ sensing $^{8-10}$ and energy storage. ${ }^{3,11}$ However, many 3D macroporous graphene materials collapse easily, and the assembly of a robust structure is still a challenge. ${ }^{2}$ In recent years, numerous attempts have been made to incorporate graphene oxide (GO) and/or reduced graphene oxide (RGO) into functional polymers for mechanical enhancement. Besides, the resultant graphene-polymer hybrids not only retain some physiochemical properties of the individual components, but also are endowed with some novel

${ }^{a}$ Colleges and Universities Key Laboratory of Food Safety and Detection, College of Chemistry and Bioengineering, Guilin University of Technology, Guilin, Guangxi, 541004, China.E-mail: guihuaruan@hotmail.com

${ }^{b}$ Collaborative Innovation Center for Water Pollution Control and Water Safety in Karst Area, Guilin, Guangxi, 541004, China

${ }^{c}$ School of Biomedical Engineering, Southern Medical University, Guangzhou, Guangdong, 510515, China

$\dagger$ Electronic supplementary information (ESI) available. See DOI: 10.1039/c8ra01620h

\$ These authors contributed equally. characters that are different from those individual components. On account of this, GO-PVP, GO-PVA, GO-PEO, etc. have been reported. ${ }^{\mathbf{1 2 - 1 5}}$ However, the preparation of these GO-polymer 3D networks relies on high quantities of GO matrix, which results in high fabricating costs.

As an effective method to fabricate macroporous polymers, high internal phase emulsions (HIPEs) have been intensively exploited. ${ }^{\mathbf{1 6}}$ Polymers obtained from HIPE templates which are known as polyHIPEs are often endowed with high porosity, good permeability, and functional group tenability. ${ }^{17,18}$ Fabricating GO hybridized polyHIPEs (polyHIPEs/GO) is seemingly a great option to improve the structural stability of macropores and to impart many organic groups to the resultant polymers. In addition, the preparation of polyHIPEs/GO can greatly reduce the GO quantity used, which is cost-effective. But surprisingly, polyHIPEs/GO has rarely been exploited in the past years.

In this work, we firstly report the synthetic and surface manipulation strategies of polyHIPEs/GO. Then, we study the morphologies, chemical composition and thermal stability of the polymers using scanning electron microscope (SEM), Fourier transform infrared spectroscopy (FTIR), X-ray photoelectron spectroscopy (XPS), X-ray diffraction (XRD) and thermo gravimetric analysis (TGA). Furthermore, we show that the asprepared polyHIPEs/GO is useful in dye adsorption and photodegradation. 


\section{Experimental}

\subsection{Materials}

Methyl blue (MB, AR), rhodamine B (RB, AR), eosin Y (EY, AR), graphite powders (99.95\%), 2-ethylhexyl acrylate (EHA, 99\%), acrylamide (AAm, 99\%), divinylbenzene (DVB, 98\%), sorbitan monooleate (Span 80), polyvinylpyrrolidone (PVP, K-30), azobisisobutyronitrile (AIBN), and ascorbic acid (AA) were purchased from Aladdin Chemistry Co. Ltd (Shanghai, China). Sulfuric acid $\left(\mathrm{H}_{2} \mathrm{SO}_{4}, 98 \%\right)$, hydrogen peroxide $\left(\mathrm{H}_{2} \mathrm{O}_{2}, 30 \%\right)$, hydrochloric acid ( $\mathrm{HCl}, 37 \%)$, ethanol (AR), sodium nitrate $\left(\mathrm{NaNO}_{3}, \mathrm{AR}\right)$, potassium permanganate $\left(\mathrm{KMnO}_{4}, \mathrm{AR}\right)$, sodium hydroxide ( $\mathrm{NaOH}, \mathrm{AR})$, sodium hypochlorite solution ( $\mathrm{NaClO}$, 5.5\% effective chlorine), silver nitrate $\left(\mathrm{AgNO}_{3}, \mathrm{AR}\right)$, sodium phosphate dibasic dodecahydrate $\left(\mathrm{Na}_{2} \mathrm{HPO}_{4}{ }^{\cdot} 12 \mathrm{H}_{2} \mathrm{O}, \mathrm{AR}\right)$ were supplied by Chengdu XiYa Chemical Technology Co., Ltd. (Sichuan, China). Deionized (DI) water was used throughout.

\subsection{GO preparation and modification}

Graphite oxides were prepared according to the previous modified Hummer's method. ${ }^{19}$ Aqueous GO suspension $(5.0 \mathrm{mg}$ $\mathrm{mL}^{-1}$ ) was obtained by ultrasonicating the graphite oxide dispersion for $1 \mathrm{~h}$. Then, $667 \mathrm{mg}$ PVP was added into $20 \mathrm{~mL}$ of GO suspension, followed by magnetic stirring for $12 \mathrm{~h}$ at room temperature, ${ }^{20}$ then centrifuged at $15000 \mathrm{rpm}$ for $20 \mathrm{~min}$ to remove the unbound PVP. The collected slurry was redispersed in DI water with a final volume of $20 \mathrm{~mL}$.

\subsection{Synthesis of polyHIPEs/GO}

An oil phase consisting of $400 \mu \mathrm{L}$ of EHA, $300 \mu \mathrm{L}$ of DVB, $15 \mathrm{vol} \%$ (with respect to the whole volume of oil phase) of Span 80, and $1.5 \mathrm{wt} \%$ (with respect to the total mass of EHA and DVB) of initiator AIBN was added to a $3.2 \mathrm{~mL}$ of aqueous phase containing $100 \mathrm{mg}$ of AAm and $2.0 \mathrm{~mL}$ of PVP-GO in a $10 \mathrm{~mL}$ polypropylene centrifuge tube. The mixtures were emulsified with an MS-3B homogenizer (IKA, Germany) at $3000 \mathrm{rpm}$ for 5 min to form HIPEs (80\% internal phase). HIPEs with identical internal volume ratio but different AAm, DVB, and PVP-GO quantity were prepared as described in Table S1. The HIPEs were polymerized at $70{ }^{\circ} \mathrm{C}$ for $15 \mathrm{~h}$ to yield polyHIPEs/GO porous monoliths. After cooled to room temperature, the unreacted components were eliminated with ethanol and DI water, then the polymers were lyophilized at $-50{ }^{\circ} \mathrm{C}$ and $<20 \mathrm{~Pa}$ for $24 \mathrm{~h}$.

\subsection{Amination and $\mathrm{Ag}_{3} \mathrm{PO}_{4}$ decoration on polyHIPEs/GO}

Hoffman reaction ${ }^{21}$ was used for the transformation of amide groups to primary amine groups. Briefly, $1.0 \mathrm{~g}$ polyHIPEs/GO monolith was added to $10 \mathrm{~mL}$ ice water. Subsequently, $2.0 \mathrm{~mL}$ of $\mathrm{NaOH}$ solution $(1 \mathrm{M})$ and $2.0 \mathrm{~mL}$ of $\mathrm{NaClO}$ solution $(5.5 \%$ effective chlorine) were added. The reaction was carried out at $0{ }^{\circ} \mathrm{C}$ for $6.5 \mathrm{~h}$, then heated at $70{ }^{\circ} \mathrm{C}$ for $1.5 \mathrm{~h}$ with gently shaking. After the reaction, the excess $\mathrm{NaOH}$ and $\mathrm{NaClO}$ were eliminated with DI water, and the products were lyophilized. The obtained aminated polyHIPEs/GO is denoted as to polyHIPEs $\left(\mathrm{NH}_{2}\right) / \mathrm{GO}$.
The monolithic polyHIPEs ${ }_{\left(\mathrm{NH}_{2}\right)} / \mathrm{GO}$ was crushed into powders and the powders passing through the sieve (100 meshes per $\mathrm{cm}^{2}$ ) were collected. The collected powders $(50 \mathrm{mg})$ were coated with additional GO (5.0 mg) via self-assembly in $10 \mathrm{~mL}$ of water, then the GO was reduced by AA (50 mg) in a $25 \mathrm{~mL}$ Teflon-lined stainless steel autoclave at $95{ }^{\circ} \mathrm{C}$ for $3 \mathrm{~h}^{22}$ After the reaction, the autoclave was left to cool naturally to room temperature, then washed with DI water and collected by centrifugation. The obtained polyHIPEs $\left(\mathrm{NH}_{2}\right) / \mathrm{RGO}$ was dispersed in $20 \mathrm{~mL}$ of water, and $\mathrm{AgNO}_{3}$ aqueous solution (2.0 $\mathrm{mL}, 0.6 \mathrm{M}$ ) was added dropwise with magnetic stirring. After the addition, the suspension was kept stirring for further $12 \mathrm{~h}$ to ensure the adsorption of $\mathrm{Ag}^{+}$on the surface of polyHIPEs$\left(\mathrm{NH}_{2}\right) /$ RGO. Then $\mathrm{Na}_{2} \mathrm{HPO}_{4}$ aqueous solution $(2.0 \mathrm{~mL}, 0.2 \mathrm{M})$ was added dropwise to the mixture, and the mixture was kept stirring for $30 \mathrm{~min} .{ }^{23}$ PolyHIPEs $\left(\mathrm{NH}_{2}\right) / \mathrm{RGO} / \mathrm{Ag}_{3} \mathrm{PO}_{4}$ composites were obtained by collecting and freeze drying the centrifugal precipitates.

\subsection{Characterizations}

Atomic force microscope (AFM) images of PVP-GO were obtained using a Multimode 8 in the tapping mode. The PVP-GO sample was dispersed in water and spin coating onto freshly cleaved mica substrates before the test. FTIR spectra were recorded in $\mathrm{KBr}$ pellets using an IS10 FTIR spectrometer (Thermo Fisher Scientific Co., USA). Surface morphologies of the samples were observed by a SU5000 field emission SEM (Hitachi Ltd, Japan). Powder XRD spectra were recorded using a PANalytical $\mathrm{X}^{\prime}$ Pert $^{3}$ Powder diffractometer with $\mathrm{Cu} \mathrm{K} \alpha$ radiation at $40 \mathrm{kV}$ and $40 \mathrm{~mA}$, and a scanning rate of $5^{\circ}(2 \theta) / \mathrm{min}$ from $10^{\circ}$ to $80^{\circ}$. TGA was carried out using TA Instruments (SDT Q 600) at a heating rate of $10{ }^{\circ} \mathrm{C} \min ^{-1}$ from $25{ }^{\circ} \mathrm{C}$ to $600{ }^{\circ} \mathrm{C}$ in nitrogen atmosphere. XPS spectra were obtained with an Axis Ultra DLD (Kratos Ltd, U.K.) paired with a monochromatic Al Ka X-ray source $(1486.6 \mathrm{eV})$.

\subsection{Dye adsorption and desorption}

Two cationic dyes (MB and $\mathrm{RB}$ ) and one anionic dye (EY) were employed to investigate the adsorption behaviors of the polyHIPEs/GO and polyHIPEs $\left.\mathrm{(NH}_{2}\right)$ GO. Typically, the monolithic sorbent $(0.1 \mathrm{~g})$ was added into aqueous dye solution (20 mL of $10 \mu \mathrm{g} \mathrm{mL}^{-1}$ ), followed by gently shaking at room temperature. At predetermined time intervals, the dye concentration remaining in the solution was measured using a TU$1901 \mathrm{UV}$-Vis spectrophotometer at the maximum absorbance of each dye (MB: $664 \mathrm{~nm}$; RB: $557 \mathrm{~nm}$; EY: $515 \mathrm{~nm}$ ). The adsorption amount at time $t, q_{t}\left(\mu \mathrm{g} \mathrm{g}^{-1}\right)$, was calculated using the following equation:

$$
q_{t}=V\left(C_{0}-C_{t}\right) / m
$$

where $V$ is the volume of dye solution $(\mathrm{mL}) ; C_{0}$ and $C_{t}\left(\mu \mathrm{g} \mathrm{mL}^{-1}\right)$ are the dye concentration initially and at time $t$, respectively; and $m$ stands for the mass of the sorbent $(\mathrm{g})$.

A mixed dye solution (50 mL) containing $10 \mu \mathrm{g} \mathrm{mL}^{-1}$ of $\mathrm{MB}$, $\mathrm{RB}$ and EY was successively passed through a polyHIPEs$\left(\mathrm{NH}_{2}\right) /$ 
GO column and two polyHIPEs/GO columns under different $\mathrm{pH}$ values (Fig. 1). The columns used in all processes were $0.2 \mathrm{~g}$ in weight and $\sim 4 \mathrm{~mm}$ in length, and the filtration rate is controlled at $0.1 \mathrm{~mL} \mathrm{~min}^{-1}$. The $\mathrm{pH}$ of the solution was adjusted using $0.1 \mathrm{MHCl}$ and $\mathrm{NaOH}$. UV-Vis spectra of the solution at different filtration stages were all recorded.

\subsection{Photocatalytic study}

A $350 \mathrm{~W}$ Xe lamp (XPA-4 Photoreactor) equipped with a cutoff filter $(\lambda>420 \mathrm{~nm})$ was used as irradiation source. Dye solutions $\left(20 \mathrm{~mL}, 3.5 \times 10^{-5} \mathrm{M}\right)$ containing $20 \mathrm{mg}$ of photocatalysts were put in a cylindrical glass beaker and stirred in the dark to reach absorption-desorption equilibrium. Next, Xe lamp was turned on to start the photocatalytic reaction. At regular time intervals, Xe lamp was turned off and $4 \mathrm{~mL}$ of the solution was taken out and centrifuged to separate the photocatalyst. Then UV-Vis spectra of the supernatant were recorded. After that, the solution was pour back in the beaker. The photocatalytic reaction and supernatant analysis processes were repeated until the dyes were degraded completely. The degradation efficiency was evaluated by $C_{t} / C_{0}$. Here, $C_{t}$ and $C_{0}$ are the concentration (M) of dyes at time $t(\mathrm{~min})$ and initially.

\section{Results and discussion}

\subsection{Characterization of polymers and composites}

The dispersibility and sheet thickness of PVP-GO were collected using atomic force microscopy. As shown in Fig. S1, $\uparrow$ PVP-GO sheets remain good dispersibility in water, and the thickness is less than $1 \mathrm{~nm}$. The sheet edge tends to curl up, causing the significant increase in vertical thickness. Morphologies of the HIPE-based polymers and $\mathrm{Ag}_{3} \mathrm{PO}_{4}$-based composites were observed by SEM. Fig. 2a and $\mathrm{b}$ reveal the open-cell porous structure of polyHIPEs/GO and polyHIPEs $\left(\mathrm{NH}_{2}\right) / \mathrm{GO}$. Spherical voids with tens of microns in diameter are derived from the emulsion droplets. Many circular windows existing in the void surface interconnect the adjacent voids. Besides, a myriad of nanoscale to submicroscale grooves are also found in the wall (Fig. S2 $\dagger$ ). Because the relatively low PVP-GO content and the non-transparency of the polyHIPEs matrix, it is unfeasible to directly observe the distribution of PVP-GO sheets under SEM or TEM, unless the PVP-GO sheets are aggregated on the surface. According to Fig. 2a and b, no aggregated PVP-GO sheets can be seen, we can presume that the amphiphilicity of

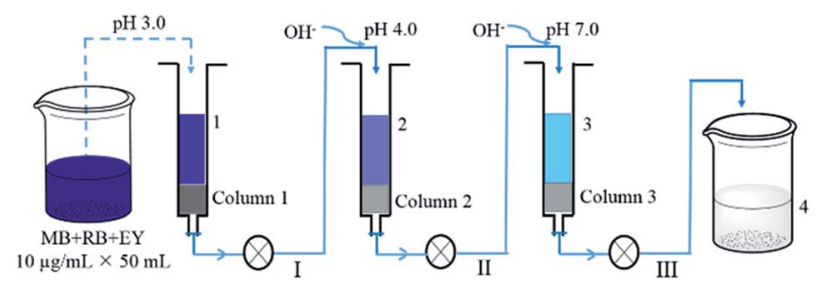

Fig. 1 Schematic illustration of the adsorption of mixed dye solution by polyHIPEs $\left(\mathrm{NH}_{2}\right) / \mathrm{GO}$ (column 1) and polyHIPEs/GO (column 2 and 3) tandem columns.
PVP-GO is uniformly located at the surface between oil phase and aqueous phase of an emulsion. TGA results (Fig. 2e) reveal that the incorporation of GO can apparently enhance the thermal stability of the polymers. The thermal degradation of polyHIPEs and polyHIPEs/GO happens mainly in the range of $230-430{ }^{\circ} \mathrm{C}$ and $350-480{ }^{\circ} \mathrm{C}$, respectively. This in turn demonstrates our previous presumption, because $\mathrm{GO}$ can act as an excellent barrier to protect the inner polymer matrix from thermal degradation before $350{ }^{\circ} \mathrm{C}$ only when GO is uniformly located at the surface. ${ }^{24}$ The amination further increases the degradation temperature (37\% of the weight for polyHIPEs $\left(\mathrm{NH}_{2}\right) /$ $\mathrm{GO}$ is remained even at $600{ }^{\circ} \mathrm{C}$ ), revealing the higher thermal stability of amines to amides. In Fig. 2c, as the RGO content is increased (compared with the GO content in Fig. $2 a$ and b), the RGO layer is observable. Fig. 2c clearly shows the hierarchical structure of polyHIPEs $\left(\mathrm{NH}_{2}\right) / \mathrm{RGO} / \mathrm{Ag}_{3} \mathrm{PO}_{4}$. The RGO layer avoids the direct contact of polyHIPEs $\left(\mathrm{NH}_{2}\right)$ and $\mathrm{Ag}_{3} \mathrm{PO}_{4}$. The particle size of $\mathrm{Ag}_{3} \mathrm{PO}_{4}$ in polyHIPEs $\left(\mathrm{NH}_{2} / \mathrm{RGO} / \mathrm{Ag}_{3} \mathrm{PO}_{4}\right.$ hybrids has a distinct decrease compared with that of bared $\mathrm{Ag}_{3} \mathrm{PO}_{4}$ (Fig. S3†). This phenomenon is consistent with the precious report which revealed that GO has an obvious effect on the size of $\mathrm{Ag}_{3} \mathrm{PO}_{4}$ particles. ${ }^{23}$ The XRD pattern (Fig. 2f) for polyHIPEs $\left(\mathrm{NH}_{2}\right) / \mathrm{RGO} / \mathrm{Ag}_{3} \mathrm{PO}_{4}$ clearly shows all characteristic diffraction peaks that could be readily indexed to the bodycentered cubic structure of $\mathrm{Ag}_{3} \mathrm{PO}_{4}$ (JCPDS no. 06-0505), demonstrating the same structure of $\mathrm{Ag}_{3} \mathrm{PO}_{4}$ in these two samples despite their different particle sizes.

In Fig. 2d, the FTIR spectrum of GO shows absorption bands at $1722 \mathrm{~cm}^{-1}\left(\nu_{\mathrm{OC}}=\mathrm{O}\right), 1400 \mathrm{~cm}^{-1}\left(\nu_{\mathrm{C}-\mathrm{OH}}\right)$, and $1090 \mathrm{~cm}^{-1}$ $\left(\nu_{\mathrm{C}-\mathrm{O}-\mathrm{C}}\right)$, depicting the existence of the carboxyl, hydroxyl and epoxy groups. ${ }^{25}$ Absorption peaks at $2970 \mathrm{~cm}^{-1}\left(\nu_{\mathrm{C}-\mathrm{H}}\right)$, $1663 \mathrm{~cm}^{-1}\left(\nu_{\mathrm{NC}=\mathrm{O}}\right)$ and $1289 \mathrm{~cm}^{-1}\left(\nu_{\mathrm{N}-\mathrm{C}}\right)^{26}$ in the FTIR spectrum of PVP-GO confirms the PVP chains were successfully modified onto the GO sheets. According to the change in relative peak intensity at $1734 \mathrm{~cm}^{-1}\left(\nu_{\mathrm{OC}=\mathrm{O}}\right)$ and $1667 \mathrm{~cm}^{-1}\left(\nu_{\mathrm{NC}=\mathrm{O}}\right)$ in FTIR spectra of polyHIPEs and polyHIPEs/GO, we can presume the presence of PVP-GO in the polymer matrix. In the FTIR spectrum of polyHIPEs $\left.\mathrm{(NH}_{2}\right) / \mathrm{GO}$, the decreased absorption at $1667 \mathrm{~cm}^{-1}\left(\nu_{\mathrm{NC}=\mathrm{O}}\right)$ and the appeared absorption at $1562 \mathrm{~cm}^{-1}$ $\left(\delta_{\mathrm{N}-\mathrm{H}}\right)$ proves that amides have translated to amines. ${ }^{21}$ The absorption peak corresponded to $\mathrm{PO}_{4}{ }^{3-}\left(1076 \mathrm{~cm}^{-1}\right)$ in the FTIR spectrum of polyHIPEs $\left(\mathrm{NH}_{2}\right) / \mathrm{RGO} / \mathrm{Ag}_{3} \mathrm{PO}_{4}$ demonstrates the presence of $\mathrm{Ag}_{3} \mathrm{PO}_{4}$ in the hybrids. ${ }^{27}$ To prove the GO has been reduced in polyHIPEs $\left(\mathrm{NH}_{2}\right) / \mathrm{RGO} / \mathrm{Ag}_{3} \mathrm{PO}_{4}$, high resolution C1s XPS spectra of polyHIPEs $\left(\mathrm{NH}_{2}\right) / \mathrm{GO}$ and polyHIPEs $\left(\mathrm{NH}_{2}\right) / \mathrm{RGO} /$ $\mathrm{Ag}_{3} \mathrm{PO}_{4}$ samples were collected (Fig. $2 \mathrm{~g}$ and $\mathrm{h}$ ). Peak intensity corresponding to carbons singly bonded to epoxy/hydroxyls (C$\mathrm{O}, 286.5 \mathrm{eV})$ and carbons in carboxyl/ester groups $(\mathrm{O}-\mathrm{C}=\mathrm{O}$, $288.9 \mathrm{eV})^{22}$ in the C1s XPS spectrum of polyHIPEs $\left(\mathrm{NH}_{2}\right) / \mathrm{RGO} /$ $\mathrm{Ag}_{3} \mathrm{PO}_{4}$ is decreased compared with that in polyHIPEs $\mathrm{N}_{\left(\mathrm{NH}_{2}\right)} / \mathrm{GO}$, confirming the reduction of GO. The remaining intensity at 286.5 and $288.9 \mathrm{eV}$ is ascribed to the $\mathrm{C}-\mathrm{O}$ and $\mathrm{O}-\mathrm{C}=\mathrm{O}$ from the polymer matrix that cannot be reduced by ascorbic acid. The reduction of oxygen-containing groups on $\mathrm{GO}$ sheets forms $\mathrm{C}=$ $\mathrm{C}$, leading to a slightly broadening to higher binding energy in the peak associated with $\mathrm{C}-\mathrm{C}$ and $\mathrm{C}=\mathrm{C}$. 

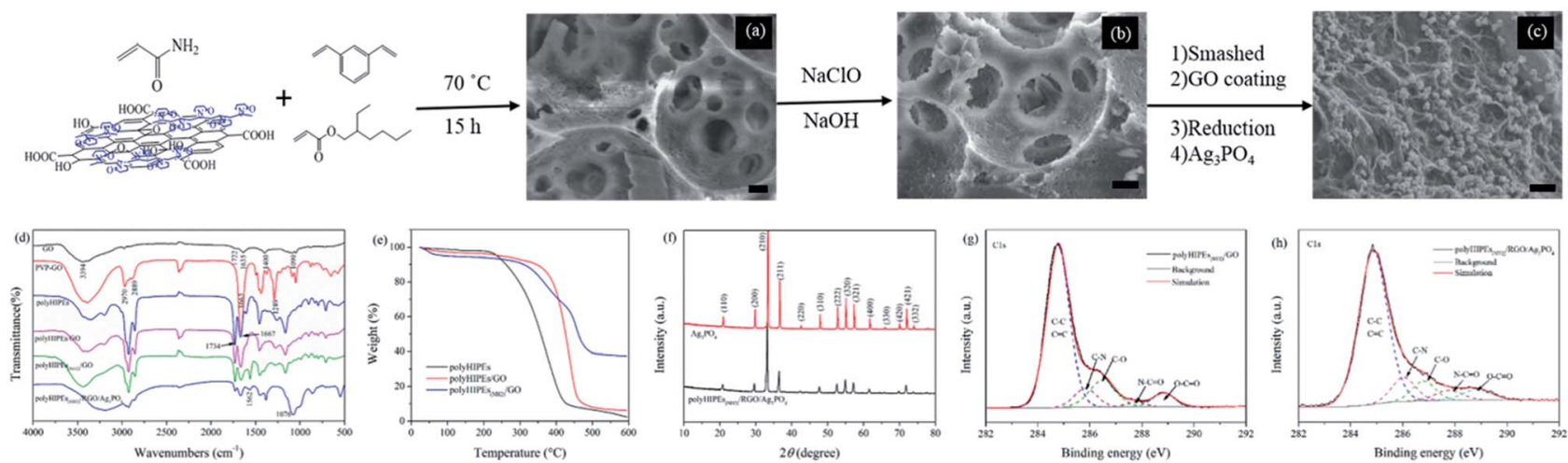

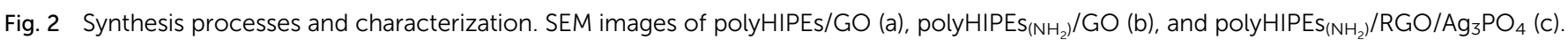
Scale bars all are $10 \mu \mathrm{m}$. FTIR spectra of the prepared materials (d), TGA curves for polyHIPE, polyHIPEs/GO and polyHIPEs( $\mathrm{NH}_{2} / \mathrm{GO}(\mathrm{e}), \mathrm{XRD}$

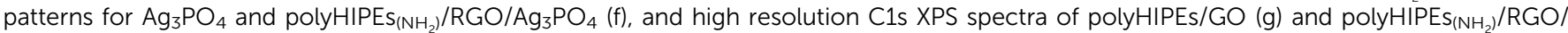

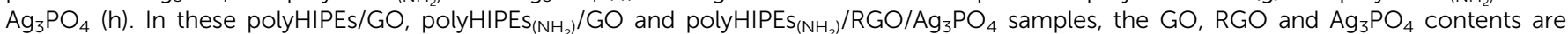
$1.35 \mathrm{wt} \%, 4.6 \mathrm{wt} \%$ and $49.7 \mathrm{wt} \%$, respectively.

\subsection{Dye adsorption}

Dye removal behaviors of monolithic polyHIPEs/GO and polyHIPEs$_{\left(\mathrm{NH}_{2}\right)} / \mathrm{GO}$ were investigated using two cationic dyes (MB and $\mathrm{RB}$ ) and an anionic dye (EY) as models. Since the adsorption of dyes on these sorbents is expected to have great connections with surface charge, effect of $\mathrm{pH}$ on the adsorption capacity was firstly investigated. As shown in Fig. 3a, the adsorption of $\mathrm{MB}$ and $\mathrm{RB}$ on polyHIPEs (without any GO) is rather weak and varies little as the $\mathrm{pH}$ is increased. Differently, the adsorption of EY on polyHIPEs $\left(\mathrm{NH}_{2}\right)$ decreases when the $\mathrm{pH}$ is increased from 1.0 to 5.0 , then remains a constant. After GO is combined with polyHIPEs or polyHIPEs $\left(\mathrm{NH}_{2}\right)$, the adsorption capacity to these dyes enhances significantly. The adsorption of cationic MB on polyHIPEs/GO enhances with the increase in $\mathrm{pH}$ value, and the maximum adsorption amount is obtained when the $\mathrm{pH} \geq 7.0$, because the deprotonation of carboxyl and hydroxyl groups trigger the electrostatic interactions (Fig. S4 $\dagger$ ). Differently, the maximum adsorption of $\mathrm{RB}$ appears at the $\mathrm{pH}$ range of 3.0-5.0. This is because the highest deprotonation of carboxyl groups in $\mathrm{RB}$ molecules at high $\mathrm{pH}$ range inversely leads to the weak positive charge of the whole molecule, weakening the electrostatic interactions. Strongest electrostatic interaction between RB molecule and polyHIPEs/GO is achieved under weakly acidic condition due to carboxyl groups are
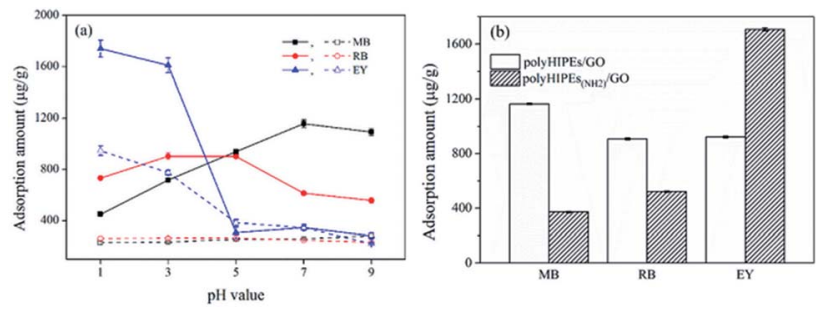

Fig. 3 Investigation of $\mathrm{pH}$ on the adsorption of dyes. (a) Effect of $\mathrm{pH}$ on the adsorption capacity of polyHIPEs (dashed line) and polyHIPEs/ $\mathrm{GO}$ (solid line) to $\mathrm{MB}$ and $\mathrm{RB}$, and polyHIPEs $\mathrm{NH}_{\left(\mathrm{NH}_{2}\right)}$ (dashed line) and polyHIPEs $\left(\mathrm{NH}_{2}\right) / \mathrm{GO}$ (solid line) to EY, (b) adsorption capacity of polyHIPEs/GO and polyHIPEs $\left(\mathrm{NH}_{2}\right) / \mathrm{GO}$ under optimized $\mathrm{pH}$. The GO content in polyHIPEs/GO and polyHIPEs $\left(\mathrm{NH}_{2}\right) / \mathrm{GO}$ is $1.35 \mathrm{wt} \%$. partially deprotonated. When we use polyHIPEs$\left(\mathrm{NH}_{2}\right) / \mathrm{GO}$ to absorb the anionic EY, the highest adsorption amount is achieved when the $\mathrm{pH} \leq 3.0$, where amine, hydroxyl and epoxy on the sorbent are protonated, leading to a strong electrostatic interaction with the anionic EY. Under the optimized $\mathrm{pH}$, the maximum adsorption amount of polyHIPEs $\left(\mathrm{NH}_{2}\right) / \mathrm{GO}$ to $\mathrm{MB}$ and $\mathrm{RB}$ is significantly lower than that of polyHIPEs/GO, while the maximum adsorption amount of polyHIPEs $\left.\mathrm{(NH}_{2}\right) / G O$ to EY is much higher than that of polyHIPEs/GO (Fig. 3b), well demonstrating the reasonability of employing polyHIPEs/GO and polyHIPEs $\left.\mathrm{(NH}_{2}\right) / \mathrm{GO}$ for the adsorption of cationic dyes and anionic dyes, respectively.

To understand the adsorption mechanism in depth, the quantity of AAm, DVB and GO were investigate. It was found that the adsorption capacity of polyHIPEs$\left(\mathrm{NH}_{2}\right) / \mathrm{GO}$ to EY heightens with the ascendent quantity of AAm, however, the increased AAm quantity has less effects on the adsorption capacity of polyHIPEs/GO to MB and RB (Fig. 4a). This prove that the amide groups have little effects on the adsorption of cationic dyes. When amide groups are transformed to amine groups, the protonated amine groups contribute to the electrostatic attraction with the anionic EY. The increase in DVB quantity ends with higher adsorption capacity of both polyHIPEs/GO and polyHIPEs ${\left(\mathrm{NH}_{2}\right)} / \mathrm{GO}$ (Fig. 4b), revealing the $\pi-$ $\pi$ interaction adsorption mechanism. Increasing in GO quantity can enhance both the electrostatic interaction and $\pi-\pi$ interaction, which is supported by the result that the adsorption amount of $\mathrm{MB}, \mathrm{RB}$, and $\mathrm{EY}$ all ascends when the GO quantity rises from 0 to $10 \mathrm{mg}$ (Fig. 4c). Nonetheless, further increase in
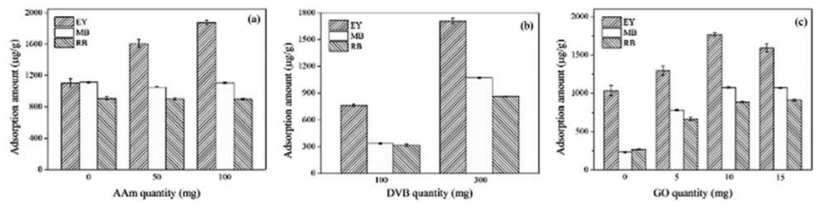

Fig. 4 Effects of the quantity of AAm (a), DVB (b) and GO (c) on the adsorption capacity of polyHIPEs/GO to $M B$ and RB, and polyHIPEs $\left(\mathrm{NH}_{2}\right) / \mathrm{GO}$ to EY. 
GO quantity cannot obtain higher adsorption capacity probably due to the aggregation of GO and some of the GO sheets are unable to show their functions.

The dye adsorption on polyHIPEs/GO and polyHIPEs $\mathrm{NH}_{\left(\mathrm{NH}_{2}\right)} / \mathrm{GO}$ follows the pseudo-second-order kinetic model (Fig. S5 $\dagger$ ). The saturated adsorption capacity $\left(q_{e}\right)$ of polyHIPEs/GO to MB and RB, polyHIPEs $\left(\mathrm{NH}_{2}\right)$ GO to EY are calculated to be 1250.3, 1054.1, $1967.3 \mu \mathrm{g} \mathrm{g}^{-1}$, respectively. The adsorption rate constants $(k)$ to $\mathrm{MB}, \mathrm{RB}$ and $\mathrm{EY}$ are $2.30 \times 10^{-4}, 2.38 \times 10^{-4}$ and $1.49 \times 10^{-4}$ (Table S2). In addition, the polymer sorbents adsorbed with dyes are ease of releasing the dyes in ethanol (desorption efficiencies $>87 \%$ ), and thus possess good cycling performance (Fig. S6 $\dagger^{\dagger}$ and $\mathrm{S} 7 \dagger$ ). As pointed in Table S3, polyHIPEs/GO and polyHIPEs $\left(\mathrm{NH}_{2}\right) / \mathrm{GO}$ exhibit superiorities including the broadspectrum adsorption ability, simple synthesis procedure, lowcost of the monolithic sorbent and good recycling performance when compared with the powder-like, aerogel, or hydrogel sorbents. The relatively low adsorption capacity of the as-prepared sorbents probably because the higher bulk density compared with the light weight aerogel and GO rich sorbents. When the adsorption capacity is evaluated by the dye quantity adsorbed in per gram sorbent, the light weight sorbent possessing a much larger volume benefits a higher uptake of dyes. To address the low adsorption capacity, continuous research will be carried out in the future.

The removal of dyes from water were further studied using the polyHIPEs/GO and polyHIPEs $\left(\mathrm{NH}_{2}\right)$ /GO as column packing. As illustrated in Fig. 1, a mixed solution containing $\mathrm{MB}, \mathrm{RB}$ and EY was successively passed through the polyHIPEs $\left(\mathrm{NH}_{2}\right) / \mathrm{GO}$ column at $\mathrm{pH} 3.0$, polyHIPEs/GO column at $\mathrm{pH} 4.0$, and polyHIPEs/GO column at $\mathrm{pH} 7.0$. Fig. 5 showed that $77 \%$ of EY, $55 \%$ of $\mathrm{RB}$ and $5 \%$ of $\mathrm{MB}$ were filtered by polyHIPEs$\left(\mathrm{NH}_{2}\right) / \mathrm{GO}$ column at $\mathrm{pH} 3.0$. Subsequently, the remaining $23 \%$ of $\mathrm{EY}, 45 \%$ of $\mathrm{RB}$ and $31 \% \mathrm{MB}$ were further filtered after passing the polyHIPEs/GO column at $\mathrm{pH} 4.0$. Finally, the rest of $63 \%$ of $\mathrm{MB}$ were eliminated by polyHIPEs/GO column at $\mathrm{pH}$ 7.0. This result suggests that various dyes in the polluted water can be selective filtered via the tandem use of polyHIPEs$\left(\mathrm{NH}_{2}\right) / \mathrm{GO}$ and
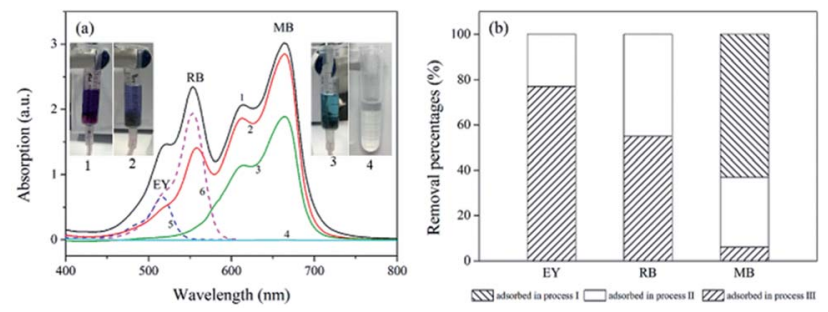

Fig. 5 The filtration of dyes using polyHIPE $\left(\mathrm{NH}_{2}\right) / \mathrm{GO}$ and polyHIPEs/ GO columns. (a) UV-Vis spectra of the dye solution at different adsorption processes. Spectra 1-4 correspond to the original mixed dye solutions ( $50 \mathrm{~mL} \times 10 \mu \mathrm{g} \mathrm{mL}^{-1}$ of $\mathrm{MB}, \mathrm{RB}$, and $\mathrm{EY}$ ), solution passed through polyHIPE $\left.\mathrm{(NH}_{2}\right) / \mathrm{GO}$ column at $\mathrm{pH}$ 3.0, solution passed through polyHIPEs/GO column at $\mathrm{pH} 4$.0, solution passed through polyHIPEs/ $\mathrm{GO}$ column at $\mathrm{pH} 7.0$, spectra 5 and 6 are solo $\mathrm{EY}$ and RB, respectively. (b) Adsorption percentages of EY, RB and MB in processes I-III illustrated in Fig. 1. The GO content in polyHIPEs/GO and polyHIPEs $\left(\mathrm{NH}_{2}\right) /$ GO is $1.35 \mathrm{wt} \%$.
polyHIPEs/GO columns. Moreover, the polluted solution can recover to neutral after such treatment.

\subsection{Photocatalytic performance of polyHIPEs $\mathbf{N H}_{\left(\mathrm{NH}_{2}\right)} / \mathrm{RGO} /$ $\mathrm{Ag}_{3} \mathrm{PO}_{4}$}

Using polyHIPEs $\left(\mathrm{NH}_{2}\right) / \mathrm{GO}$, we successfully prepared polyHIPEs$\left(\mathrm{NH}_{2}\right) /$ $\mathrm{RGO} / \mathrm{Ag}_{3} \mathrm{PO}_{4}$ composites and studied their photocatalytic performance. To our delight, polyHIPEs $\left(\mathrm{NH}_{2}\right) / \mathrm{RGO} / \mathrm{Ag}_{3} \mathrm{PO}_{4}$ exhibits significantly enhanced visible-light photocatalytic activity for $\mathrm{MB}$ degradation than that of polyHIPEs $\left(\mathrm{NH}_{2}\right) / \mathrm{Ag}_{3} \mathrm{PO}_{4}$ and $\mathrm{RGO} / \mathrm{Ag}_{3} \mathrm{PO}_{4}$ (Fig. 6a). Further study proved that the hierarchical polyHIPEs$\left(\mathrm{NH}_{2}\right) /$ $\mathrm{RGO} / \mathrm{Ag}_{3} \mathrm{PO}_{4}$ possesses good photodegradation ability to other dyes including RB and EY (Fig. 6b). Photodegradation efficiency of MB over polyHIPEs $\left(\mathrm{NH}_{2}\right) / \mathrm{RGO} / \mathrm{Ag}_{3} \mathrm{PO}_{4}$ decreases slightly after three or more cycles (Fig. $6 \mathrm{c}$ ), revealing the photocatalytic stability of polyHIPEs $\left(\mathrm{NH}_{2}\right) / \mathrm{RGO} / \mathrm{Ag}_{3} \mathrm{PO}_{4}$. Moreover, our polyHIPEs $\left(\mathrm{NH}_{2}\right) / \mathrm{RGO} /$ $\mathrm{Ag}_{3} \mathrm{PO}_{4}$ (49.7 wt\% of $\mathrm{Ag}_{3} \mathrm{PO}_{4}$ ) shows comparable or even higher photocatalytic efficiency to other well-known photocatalysts (mostly contain $>90 \mathrm{wt} \%$ semiconductors), such as $\mathrm{RGO} / \mathrm{BiVO}_{4},{ }^{28}$ $\mathrm{RGO} / \mathrm{CdS},{ }^{29} \mathrm{RGO} / \mathrm{TiO}_{2},{ }^{30,31} \mathrm{GO} / \mathrm{Ag}_{3} \mathrm{PO}_{4},{ }^{27,32}$ and $\mathrm{RGO} / \mathrm{Ag}_{3} \mathrm{PO}_{4}$ (ref. 23) (Table S4). In this status, our polyHIPEs $\left(\mathrm{NH}_{2}\right) / \mathrm{RGO} / \mathrm{Ag}_{3} \mathrm{PO}_{4}$ not only greatly reduces the synthesis cost, but maintains high photocatalytic activity.

It is known that the bandgap of $\mathrm{Ag}_{3} \mathrm{PO}_{4}$ semiconductor is $2.45 \mathrm{eV}$ (conduction band, $\mathrm{CB}:+0.45 \mathrm{eV}$; valence band, VB: +2.9 $\mathrm{eV})^{33}$ The possible photodegradation processes are illustrated in Fig. 6d: (1) under visible-light irradiation, the electrons at the VB of $\mathrm{Ag}_{3} \mathrm{PO}_{4}$ are excited to the $\mathrm{CB}$, leading to the separation of electronhole pairs. (2) Photogenerated electrons at the surface of $\mathrm{Ag}_{3} \mathrm{PO}_{4}$ are rapidly transferred by $\mathrm{RGO}$, preventing the recombination of the electron-hole pairs and accelerating the formation of a steady
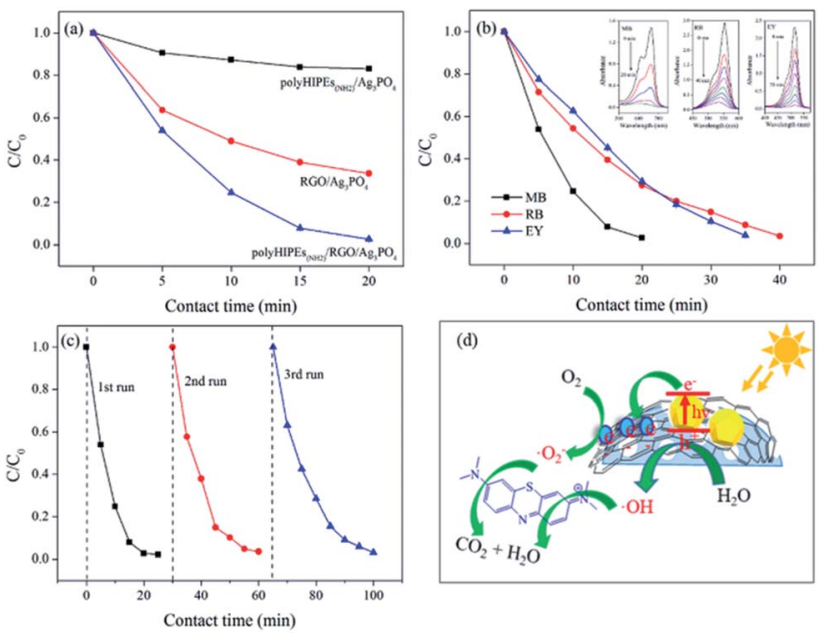

Fig. 6 Photocatalytic performance of polyHIPEs$\left(\mathrm{NH}_{2}\right) / \mathrm{RGO} / \mathrm{Ag}_{3} \mathrm{PO}_{4}$. (a) Photodegradation of $\mathrm{MB}$ over polyHIPEs$\left(\mathrm{NH}_{2}\right) / \mathrm{Ag}_{3} \mathrm{PO}_{4}, \mathrm{RGO} / \mathrm{Ag}_{3} \mathrm{PO}_{4}$ and polyHIPEs $\left(\mathrm{NH}_{2}\right) / \mathrm{RGO} / \mathrm{Ag}_{3} \mathrm{PO}_{4}$. (b) Photodegradation of $\mathrm{MB}, \mathrm{RB}$ and EY over polyHIPES$\left(\mathrm{NH}_{2}\right) / \mathrm{RGO} / \mathrm{Ag}_{3} \mathrm{PO}_{4}$, and adsorption spectra of $\mathrm{MB}$, $\mathrm{RB}$ and EY over polyHIPEs$\left(\mathrm{NH}_{2}\right) / \mathrm{RGO} / \mathrm{Ag}_{3} \mathrm{PO}_{4}$ in inset. (c) Cycling performance for photodegradation of $\mathrm{MB}$ over polyHIPEs$\left(\mathrm{NH}_{2}\right) / \mathrm{RGO} /$ $\mathrm{Ag}_{3} \mathrm{PO}_{4}$ under visible light irradiation. (d) Schematic illustration of the photocatalytic mechanism of polyHIPEs $\left(\mathrm{NH}_{2}\right) / \mathrm{RGO} / \mathrm{Ag}_{3} \mathrm{PO}_{4}$. (Photocatalysts: $20 \mathrm{mg}$, dye solutions: $20 \mathrm{~mL}$ with a concentration of $3.5 \times$ $\left.10^{-5} \mathrm{M}\right)$. 
flow of electron-hole pairs. (3) Once the photogenerated electrons are captured by $\mathrm{O}_{2}$ molecules, superoxide radicals $\left(\mathrm{O}_{2}{ }^{-\bullet}\right)$ are produced. At the same time, hydroxyl radicals $(\cdot \mathrm{OH})$ generates from the reaction of $\mathrm{H}_{2} \mathrm{O}$ and the active holes. ${ }^{23,34}$ (4) Organic dyes are attracted to the surface of polyHIPEs $\left(\mathrm{NH}_{2}\right) / \mathrm{RGO} / \mathrm{Ag}_{3} \mathrm{PO}_{4}$ due to the good adsorption behavior of the polymer, which accelerates the reaction of dye molecules and radicals. (5) By continuously working in the aforementioned manners, dye molecules are finally degraded into $\mathrm{CO}_{2}, \mathrm{H}_{2} \mathrm{O}$ and other small molecules., ${ }^{30,35}$

\section{Conclusions}

We have successfully prepared a versatile polyHIPEs/GO porous polymer with tunable properties for multiply progressive applications. This presented polyHIPEs/GO shows good adsorption performance to cationic dyes. After simply tuning the surface groups, the resultant polyHIPEs $\left(\mathrm{NH}_{2}\right) / \mathrm{GO}$ exhibits improved adsorption properties to anionic dyes. The adsorption mechanisms, adsorption kinetics, and cycling performance of these two sorbents have been systematically investigated and discussed. Furthermore, we reported a novel polyHIPEs $\mathrm{N}_{\left(\mathrm{NH}_{2}\right)} /$ $\mathrm{RGO} / \mathrm{Ag}_{3} \mathrm{PO}_{4}$ with enhanced visible-light photocatalytic activity by RGO coating and $\mathrm{Ag}_{3} \mathrm{PO}_{4}$ decoration on the surface of polyHIPEs $\left(\mathrm{NH}_{2}\right) / \mathrm{GO}$. Our work suggests that the new polyHIPEs/ GO porous polymer can be used as sorbents, filters, and photocatalysts.

\section{Conflicts of interest}

There are no conflicts to declare.

\section{Acknowledgements}

This work was supported by the National Natural Science Foundation of China (Grant No. 21665006, 21465008), the Natural Science Foundation from Guangxi Zhuang Autonomous Region (No. 2017GXNSFAA198236 and 2015GXNSFFA139005), and the project of high level innovation team and outstanding scholar in Guangxi colleges and universities (Guijiaoren[2014] 49).

\section{Notes and references}

1 H.-P. Cong, J.-F. Chen and S.-H. Yu, Chem. Soc. Rev., 2014, 43, 7295-7325.

2 V. Chabot, D. Higgins, A. Yu, X. Xiao, Z. Chen and J. Zhang, Energy Environ. Sci., 2014, 7, 1564-1596.

3 Y. Zhao, C. Hu, Y. Hu, H. Cheng, G. Shi and L. Qu, Angew. Chem., 2012, 124, 11533-11537.

4 J. Zhao, W. Ren and H.-M. Cheng, J. Mater. Chem., 2012, 22, 20197-20202.

5 S. Kabiri, D. N. H. Tran, T. Altalhi and D. Losic, Carbon, 2014, 80, 523-533.

6 H. Wang, K. Sun, F. Tao, D. J. Stacchiola and Y. H. Hu, Angew. Chem., 2013, 125, 9380-9384.

7 Y. Long, C. Zhang, X. Wang, J. Gao, W. Wang and Y. Liu, J. Mater. Chem., 2011, 21, 13934-13941.
8 X. Dong, X. Wang, L. Wang, H. Song, H. Zhang, W. Huang and P. Chen, ACS Appl. Mater. Interfaces, 2012, 4, 3129-3133.

9 Y. R. Jeong, H. Park, S. W. Jin, S. Y. Hong, S.-S. Lee and J. S. Ha, Adv. Funct. Mater., 2015, 25, 4228-4236.

10 P. Costa, J. Nunes-Pereira, J. Oliveira, J. Silva, J. A. Moreira, S. A. C. Carabineiro, J. G. Buijnsters and S. LancerosMendez, Compos. Sci. Technol., 2017, 153, 241-252.

11 W. Wang, S. Guo, M. Penchev, I. Ruiz, K. N. Bozhilov, D. Yan, M. Ozkan and C. S. Ozkan, Nano Energy, 2013, 2, 294-303.

12 H.-P. Cong, P. Wang and S.-H. Yu, Chem. Mater., 2013, 25, 3357-3362.

13 L. Zhang, Z. Wang, C. Xu, Y. Li, J. Gao, W. Wang and Y. Liu, J. Mater. Chem., 2011, 21, 10399-10406.

14 H. Bai, C. Li, X. Wang and G. Shi, J. Phys. Chem. C, 2011, 115, 5545-5551.

15 S. Morimune-Moriya, M. Ariyoshi, T. Goto and T. Nishino, Compos. Sci. Technol., 2017, 152, 159-164.

16 N. R. Cameron, Polymer, 2005, 46, 1439-1449.

17 M. S. Silverstein, Prog. Polym. Sci., 2014, 39, 199-234.

18 V. O. Ikem, A. Menner, T. S. Horozov and A. Bismarck, Adv. Mater., 2010, 22, 3588-3592.

19 H. Ge, H. Bao, L. Zhang and G. Chen, Carbon, 2015, 82, 579589.

20 S. Guo, S. Dong and E. Wang, ACS Nano, 2010, 4, 547-555.

21 Y. Yamamoto and M. V. Sefton, J. Appl. Polym. Sci., 1996, 61, 351-358.

22 M. J. Fernández-Merino, L. Guardia, J. I. Paredes, S. VillarRodil, P. Solís-Fernández, A. Martínez-Alonso and J. M. D. Tascón, J. Phys. Chem. C, 2010, 114, 6426-6432.

23 X. Yang, H. Cui, Y. Li, J. Qin, R. Zhang and H. Tang, ACS Catal., 2013, 3, 363-369.

24 Y. Zhang, X. Zheng, H. Wang and Q. Du, J. Mater. Chem. A, 2014, 2, 5304-5314.

25 G. Yin, Z. Zheng, H. Wang, Q. Du and H. Zhang, J. Colloid Interface Sci., 2013, 394, 192-198.

26 I. Pulko, M. Kolar and P. Krajnc, Sci. Total Environ., 2007, 386, 114-123.

27 Q. Liang, Y. Shi, W. Ma, Z. Li and X. Yang, Phys. Chem. Chem. Phys., 2012, 14, 15657-15665.

28 Y. Wang, W. Wang, H. Mao, Y. Lu, J. Lu, J. Huang, Z. Ye and B. Lu, ACS Appl. Mater. Interfaces, 2014, 6, 12698-12706.

29 Z. Gao, N. Liu, D. Wu, W. Tao, F. Xu and K. Jiang, Appl. Surf. Sci., 2012, 258, 2473-2478.

30 H. Zhang, X. Lv, Y. Li, Y. Wang and J. Li, ACS Nano, 2010, 4, 380-386.

31 S. D. Perera, R. G. Mariano, K. Vu, N. Nour, O. Seitz, Y. Chabal and K. J. Balkus, ACS Catal., 2012, 2, 949-956.

32 L. Liu, J. Liu and D. D. Sun, Catal. Sci. Technol., 2012, 2, 2525-2532.

33 Z. Yi, J. Ye, N. Kikugawa, T. Kako, S. Ouyang, H. Stuartwilliams, H. Yang, J. Cao, W. Luo and Z. Li, Nat. Mater., 2010, 9, 559-564.

34 N. Zhang, Y. Zhang and Y.-J. Xu, Nanoscale, 2012, 4, 57925813.

35 J. Liu, H. Bai, Y. Wang, Z. Liu, X. Zhang and D. D. Sun, Adv. Funct. Mater., 2010, 20, 4175-4181. 